\title{
Authors of outstanding article receive Senckenberg Award!
}

We are pleased to announce, that the Alexander von Humboldt-Gedächtnispreis 2013 was awarded to authors of the following article, published in the special issue of Palaeobiodiversity and Palaeoenvironments entitled Taphonomic processes in terrestrial and marine environments (Wuttke M, Reisdorf AG (eds)):

Achim G. Reisdorf, Roman Bux, Daniel Wyler, Mark Benecke, Christian Klug, Michael W. Maisch, Peter Fornaro, Andreas Wetzel

\section{Float, explode or sink: postmortem fate of lung-breathing marine vertebrates}

Volume 92, Issue 1, pp 67-81. 10.1007/s12549-011-0067-z

\begin{abstract}
What happens after the death of a marine tetrapod in seawater? Palaeontologists and neontologists have claimed that large lung-breathing marine tetrapods such as ichthyosaurs had a lower density than seawater, implying that their carcasses floated at the surface after death and sank subsequently after leakage of putrefaction gases (or "carcass explosions"). Such explosions would thus account for the skeletal disarticulation observed frequently in the fossil record. We examined the taphonomy and sedimentary environment of numerous ichthyosaur skeletons and compared them to living marine tetrapods, principally cetaceans, and measured abdominal pressures in human carcasses. Our data and a review of the literature demonstrate that carcasses sink and do not explode (and spread skeletal elements). We argue that the normally slightly negatively buoyant carcasses of ichthyosaurs would have sunk to the sea floor and risen to the surface only when they remained in shallow water above a certain temperature and at a low scavenging rate. Once surfaced, prolonged floating may have occurred and a carcass have decomposed gradually. Our conclusions are of significance to the understanding of the inclusion of carcasses of lung-breathing vertebrates in marine nutrient recycling. The postmortem fate has essential implications for the interpretation of vertebrate fossil preservation (the existence of complete, disarticulated fossil skeletons is not explained by previous hypotheses), palaeobathymetry, the physiology of modern marine lung-breathing tetrapods and their conservation, and the recovery of human bodies from seawater.
\end{abstract}

Articles published in this journal can be honoured with the Alexander von HumboldtGedächtnispreis (6,000 Euros).

One of the former Honorary Presidents of the Senckenberg Gesellschaft für Naturforschung, the late Dr. Hanns Christian Schroeder-Hohenwarth, donated the "Alexander von Humboldt-Gedächtnispreis" for the best article in one of the Senckenberg journals.

Each year, one or two outstanding articles will be chosen by the editorial board of each Senckenberg journal. The Senckenberg advisory board then selects up to four articles which will be forwarded to an independent, international scientific board. This board evaluates the submitted articles and will finally select one article for the price. 